\title{
Unexpected Chloro-functionalized Ionic liquids- promoted Selective Conversion of Cellulose into Levulinic Acid
}

\author{
Hao Ma, * Yanhui Qiao, and Junjiang Teng * \\ A series of chloro-functionalized ionic liquids (CFILs) with chlorine groups \\ $(-\mathrm{Cl})$ on cations and chloride anions $\left(\mathrm{Cl}^{-}\right)$were synthesized and used as \\ the promotion reagents for the selective conversion of cellulose into \\ levulinic acid (LA) with the co-product of formic acid (FA). The co-operation \\ between cations and anions of CFILs was investigated intensively through \\ the variation of the structure of cations and the addition of salts with \\ different anions. 3-(3-chloropropyl)-1-methyl-imidazolium chloride (IL-3) \\ was the most appropriate additive, achieving up to $4.2 \%, 52.6 \%$, and \\ $58.7 \%$ of glucose, LA, and FA yields at $83.5 \%$ of cellulose conversion, \\ respectively.
}

Keywords: Cellulose; Chloro-functionalized ionic liquids; Levulinic acid; Formic acid

Contact information: College of Chemistry, Guangdong University of Petrochemical Technology, No. 139 Guandu $2^{\text {nd }}$ Road, Maoming 525000, P. R. China;

*Corresponding authors: thma@gdupt.edu.cn (H.Ma); tjjteng@gdupt.edu.cn (J. Teng)

\section{INTRODUCTION}

Levulinic acid (LA) is one of the most promising building blocks for organic synthesis, and it has been selected as one of the "Top 10" platform chemicals derived from lignocellulosic biomass (Bozell and Petersen 2010; Zhang et al. 2016). Direct catalytic conversion of renewable cellulose is an important route for a sustainable production of LA. However, due to the presence of extensive intra- and intermolecular hydrogen bonds, cellulose possesses a highly crystalline structure and is insoluble in most common solvents, such as water, alcohols, and esters, thus resulting in its recalcitrant nature to conversion in aqueous solution under mild conditions (Rackemann and Doherty 2011; Deng et al. 2015). At present, the efficient conversion of cellulose into LA has been achieved through the catalysis by conventional strong acids, such as $\mathrm{HCl}, \mathrm{HBr}$, and $\mathrm{H}_{2} \mathrm{SO}_{4}$, at relatively high temperature, which result in low LA selectivity, high operating costs, various equipment corrosions, and environmental pollutants (Rackemann and Doherty 2011; Zhang et al. 2016). Hence, the replacement of conventional acid catalysts with highly active catalyst materials is the most critical step in sustainably producing LA from cellulose.

In recent years, Zuo et al. (2014) synthesized a novel bi-functional catalyst, viz., sulfonated chloromethyl polystyrene resin, for converting cellulose into LA with yields up to $65.5 \%$ under the mild condition. The high catalytic activity of their catalyst can be ascribed to the co-operation between sulfonic groups $\left(-\mathrm{SO}_{3} \mathrm{H}\right)$ and chlorine groups $(-\mathrm{Cl})$, and is in good agreement with previous work on efficient catalytic hydrolysis of cellulose using a sulfonated chloromethyl polystyrene resin as the novel cellulase-mimetic catalyst reported by Shuai and Pan (2012). The - $\mathrm{Cl}$ groups on the catalyst materials play a positive effect on cellulose conversion, and are set to be the bonding sites as the binding domain of 
enzymes due to its adsorption on cellulose through the hydrogen bonds, lowering the activity energy of cellulose conversion (Shuai and Pan 2012; Zuo et al. 2014; Zhang et al. 2019). In addition, the promotion effect of chloride anion $\left(\mathrm{Cl}^{-}\right)$on conversion of cellulose into LA has also been demonstrated in the presence of solid supported acid catalyst (Potvin et al. 2011; Wang et al. 2012). It is also found that, in the absence of added acid catalysts, the $\mathrm{Cl}^{-}$anion can still promote the hydrolysis of cellulose into glucose, typically under the microwave irradiation (Shaveta et al. 2014). Hence, the preparation of catalyst materials containing both $-\mathrm{Cl}$ groups and $\mathrm{Cl}^{-}$anions can be conceived reasonably and can be considered as a promising strategy in producing LA from cellulose.

Ionic liquids (ILs), entirely composed of cations and anions, have been recognized as promising green solvents or catalysts in bio-refinery field due to their tailor-made properties (Tao et al. 2011; Zhang et al. 2016). The structure of cations including the alkyl chain length and anions plays the key role in their physicochemical behavior, such as catalytic ability, thermal stability, density, viscosity, ionic conductivity, and so on (Amarasekara 2016; Zhang et al. 2016). Herein, based on catalysis of functionalized ILs and the authors' previous works on biomass conversion (Ma et al. 2012, 2015, 2018; Teng et al. 2016), a series of novel chloro-functionalized ionic liquids (CFILs) with chloro-alkyl groups $(-\mathrm{Cl})$ on cations and $\mathrm{Cl}^{-}$anions were designed and synthesized to use as the promotion additives for conversion of cellulose into LA with the co-product of formic acid (FA) for the first time. The synergistic effect of cations and anions of CFILs on cellulose conversion is illustrated through the variation of the structure and chloro-alkyl linker of cations and the addition of salts with different anions primarily.

\section{EXPERIMENTAL}

\section{Materials}

Microcrystalline cellulose (MCC) was purchased from Alfa Aesar (Beijing, China) and dried for $24 \mathrm{~h}$ at $90^{\circ} \mathrm{C}$ under vacuum prior to use. All other reagents and solvents were of analytical grade and were purchased from J\&K Chemical Company (Beijing, China).

\section{Procedures for Synthesis of ILs}

All CFILs (Fig. 1), 3-butyl-1-methyl-imidazolium chloride (IL-1), 3-(2chloroethyl)-1-methylimidazolium chloride (IL-2), 3-(3-chloropropyl)-1-methylimidazolium chloride (IL-3), 3-(4-chlorobutyl)-1-methyl-imidazolium chloride (IL-4), 3(5-chloropentyl)-1-methyl-imidazolium chloride (IL-5), 3-(6-chlorohexyl)-1-methylimidazolium chloride (IL-6), 3-(2-chloroethyl)-1-ethyl-imidazolium chloride (IL-7), 1butyl-3-(2-chloroethyl)-imidazolium chloride (IL-8), N-(chloroethyl)-N, Ndiethylethanaminium chloride (IL-9), 3-(4-chlorobenzyl)-1-methyl-imidazolium chloride (IL-10), 1-(2-chloroethyl)-pyridinium chloride (IL-11), and 3-(2-chloroethyl)-1-methylimidazolium nitrate (IL-12), were synthesized according to reported procedures (Wilkes and Zaworotko 1992; Bonhote et al. 1996; Kilpelainen et al. 2007; Song et al. 2008), and confirmed by nuclear magnetic resonance (NMR, DRX 400; Bruker, Berlin, Germany). Thermogravimetric analysis (TG, Netzsch Sta449c; Netzsch, Selb, Germany) showed that these CFILs are thermally stable. The detailed synthesis procedures and characterization data of NMR and onset decomposition temperature $\left(T_{\mathrm{d}}\right)$ are given as follows (Table 1$)$. 


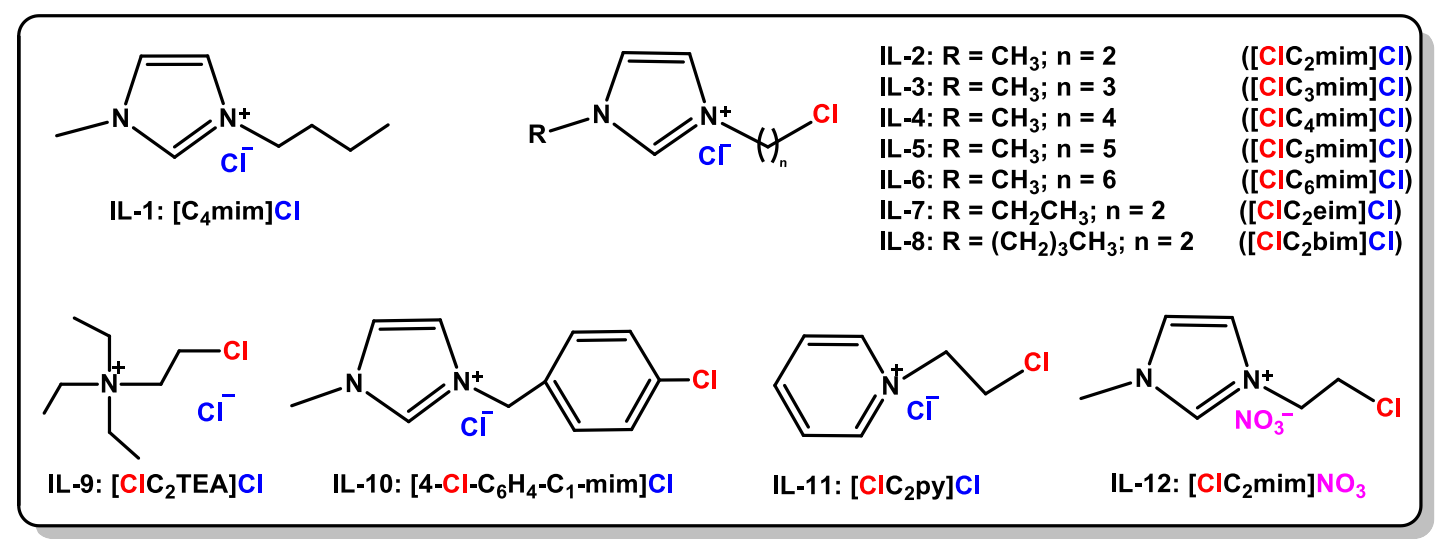

Fig. 1. The structure of CFILs used in this study

IL-1 (3-butyl-1-methyl-imidazolium chloride) was prepared according to the method reported elsewhere, and not to be described in this study (Bonhote et al. 1996).

IL-2 (3-(2-chloroethyl)-1-methylimidazolium chloride) was prepared by the reaction of 1-methylimidazole with a large excess of 1,2-dichloroethane as reported by Song et al. (2008). A mixture of 1-methylimidazole $(30 \mathrm{~mL})$ and 1,2-dichloroethane (150 $\mathrm{mL}$ ) was heated to reflux for $10 \mathrm{~h}$. The product was separated by the removal of residual 1,2-dichloroethane under vacuum and dissolved in hot acetonitrile $(400 \mathrm{~mL})$, which aimed to further remove the residual dicationic byproduct. Then, this solution was kept in a freezer overnight to give precipitates, which were mostly the dicationic byproduct. The precipitates were separated by filtration while the solution was cold, and the resulting soluble phase (filtrate) containing IL-2 was kept. After removal of all the acetonitrile of the filtrate with a rotary evaporator, the purified product was put into a vacuum drying oven to remove all the residual solvents and water at $100{ }^{\circ} \mathrm{C}$ with magnetic stirring until the weight of the product stayed unchanged. The sufficient purified product was confirmed by ${ }^{1} \mathrm{H}$ NMR and ${ }^{13} \mathrm{C}$ NMR and kept in a closed container at room temperature.

IL-3 to IL-10 were synthesized by a method directly analogous to that for IL-2, and all the ionic liquids were confirmed by ${ }^{1} \mathrm{H}$ NMR and ${ }^{13} \mathrm{C}$ NMR and kept in a closed container at room temperature (Song et al. 2008).

IL-11 (3-(4-chlorobenzyl)-1-methyl-imidazolium chloride) was prepared with benzyl chloride $(0.11 \mathrm{~mol})$ and 1-methylimidazole $(0.10 \mathrm{~mol})$ using toluene as solvent in a 250-mL three-neck bottle (Kilpelainen et al. 2007). The mixture was refluxed for $48 \mathrm{~h}$ under an air atmosphere. After evaporation of the solvent and of the residual benzyl chloride, the pure ionic liquid was obtained. The drying of the materials took place at 120 ${ }^{\circ} \mathrm{C}$ under vacuum by stirring for $24 \mathrm{~h}$. The product was of a solid gelatinous nature at room temperature.

IL-12 (3-(2-chloroethyl)-1-methyl-imidazolium nitrate) was prepared by adding $17.0 \mathrm{~g}$ of $\mathrm{AgNO}_{3}(0.1 \mathrm{~mol})$ to a solution that contained $50 \mathrm{~mL}$ of methanol and $18.1 \mathrm{~g}$ of IL-2 $(0.1 \mathrm{~mol})$ at room temperature with magnetic stirring for $10 \mathrm{~h}$ (Wilkes and Zaworotko 1992). The precipitate $(\mathrm{AgCl})$ was decanted by filtration and the filtrate was under vacuum to remove the solvent. The desired product could be obtained as a yellow liquid and was dried in a vacuum drying oven to remove all the residual solvents and water at $100{ }^{\circ} \mathrm{C}$ with magnetic stirring until the weight of the product stayed unchanged. The sufficient purified product was confirmed by ${ }^{1} \mathrm{H}$ NMR and ${ }^{13} \mathrm{C}$ NMR and kept in a closed container at the room temperature. 
Table 1. Characterization Data from NMR and TG Analysis

\begin{tabular}{|c|c|c|}
\hline CFILs & NMR & $\mathrm{T}_{\mathrm{d}}\left({ }^{\circ} \mathrm{C}\right)$ \\
\hline IL-1 & $\begin{array}{c}{ }^{1} \mathrm{H} \text { NMR }\left(400 \mathrm{MHz}, \mathrm{DMSO}-\mathrm{d}_{6}\right)(\mathrm{ppm}) \delta: 9.37(\mathrm{~s}, 1 \mathrm{H}) ; 7.83(\mathrm{~s}, 1 \mathrm{H}) ; 7.76(\mathrm{~m}, \\
1 \mathrm{H}) ; 4.19(\mathrm{t}, \mathrm{J}=6.8 \mathrm{~Hz}, 2 \mathrm{H}) ; 3.81(\mathrm{~s}, 3 \mathrm{H}) 1.73-1.81(\mathrm{~m}, 2 \mathrm{H}) ; 1.21-1.31(\mathrm{~m}, \\
2 \mathrm{H}) ; 0.90(\mathrm{t}, 3 \mathrm{H}) .{ }^{13} \mathrm{C} \text { NMR }\left(100 \mathrm{MHz}, \mathrm{DMSO}-\mathrm{d}_{6}\right) \delta: 136.62 ; 123.56 ; 122.23 ; \\
\text { 48.40; 35.69; 31.34; 18.73; } 13.25\end{array}$ & 270.2 \\
\hline IL-2 & $\begin{array}{c}{ }^{1} \mathrm{H} \text { NMR }\left(400 \mathrm{MHz}, \mathrm{DMSO}-d_{6}\right)(\mathrm{ppm}) \delta: 9.60(\mathrm{~s}, 1 \mathrm{H}) ; 7.99(\mathrm{~s}, 1 \mathrm{H}) ; 7.85(\mathrm{~s}, \\
1 \mathrm{H}) ; 4.60(\mathrm{t}, J=5.2 \mathrm{~Hz}, 2 \mathrm{H}) ; 4.12(\mathrm{t}, J=5.2 \mathrm{~Hz}, 2 \mathrm{H}) ; 3.90(\mathrm{~s}, 3 \mathrm{H}) .{ }^{13} \mathrm{C} \mathrm{NMR} \\
\left(100 \mathrm{MHz}, \mathrm{DMSO}-\mathrm{d}_{6}\right) \delta: 137.3 ; 123.7 ; 122.5 ; 50.2 ; 43.2 ; 35.8\end{array}$ & 221.8 \\
\hline IL-3 & $\begin{array}{c}{ }^{1} \mathrm{H} \text { NMR }\left(400 \mathrm{MHz}, \mathrm{DMSO}-d_{6}\right)(\mathrm{ppm}) \delta: 9.43(\mathrm{~s}, 1 \mathrm{H}) ; 7.87(\mathrm{~s}, 1 \mathrm{H}) ; 7.77(\mathrm{~s} \\
1 \mathrm{H}) ; 4.34(\mathrm{t}, J=4.0 \mathrm{~Hz}, 2 \mathrm{H}) ; 3.87(\mathrm{~s}, 3 \mathrm{H}) ; 3.68(\mathrm{t}, \mathrm{J}=4.0 \mathrm{MHz}, 2 \mathrm{H}) ; 2.29(\mathrm{q}, J \\
=4.0 \mathrm{~Hz} ; 2 \mathrm{H}) .{ }^{13} \mathrm{C} \text { NMR }\left(100 \mathrm{MHz}, \mathrm{DMSO}-\mathrm{d}_{6}\right) \delta: 137.48 ; 124.16 ; 122.79 ; \\
46.84 ; 42.21 ; 36.22 ; 32.52\end{array}$ & 247.2 \\
\hline IL-4 & $\begin{array}{c}{ }^{1} \mathrm{H} \text { NMR }\left(400 \mathrm{MHz}, \mathrm{DMSO}-d_{6}\right)(\mathrm{ppm}) \delta: 9.42(\mathrm{~s}, 1 \mathrm{H}) ; 7.86(\mathrm{~s}, 1 \mathrm{H}) ; 7.78(\mathrm{~s} \\
1 \mathrm{H}) ; 4.26(\mathrm{t}, J=4.0 \mathrm{~Hz}, 2 \mathrm{H}) ; 3.88(\mathrm{~s}, 3 \mathrm{H}) ; 3.68(\mathrm{t}, \mathrm{J}=4.0 \mathrm{~Hz}, 2 \mathrm{H}) ; 1.92 \\
\text { (quintet, } J=8.0 \mathrm{~Hz}) ; 1.70(\text { quintet, } J=8.0 \mathrm{~Hz}) .{ }^{13} \mathrm{C} \text { NMR }(100 \mathrm{MHz} \text {, DMSO- } \\
\left.d_{6}\right) \delta: 137.25 ; 124.13 ; 122.70 ; 48.41 ; 45.09 ; 36.22 ; 29.06 ; 27.43\end{array}$ & 236.7 \\
\hline IL-5 & $\begin{array}{c}{ }^{1} \mathrm{H} \mathrm{NMR}\left(400 \mathrm{MHz}, \mathrm{DMSO}-\mathrm{d}_{6}\right)(\mathrm{ppm}) \delta: 9.34(\mathrm{~s}, 1 \mathrm{H}) ; 7.83(\mathrm{~s}, 1 \mathrm{H}) ; 7.76(\mathrm{~s}, 1 \mathrm{H}) ; \\
4.20(\mathrm{t}, J=7.2 \mathrm{~Hz}, 2 \mathrm{H}) ; 3.87(\mathrm{~s}, 3 \mathrm{H}) ; 3.65(\mathrm{t}, \mathrm{J}=7.2 \mathrm{~Hz}, 2 \mathrm{H}) ; 1.83 \text { (quintet, } J= \\
7.6 \mathrm{~Hz} ; 2 \mathrm{H}) ; 1.76 \text { (quintet, } J=7.6 \mathrm{~Hz} ; 2 \mathrm{H}) ; 1.37 \text { (quintet, } J=7.2 \mathrm{~Hz} ; 2 \mathrm{H}) .{ }^{13} \mathrm{C} \\
\text { NMR }(100 \mathrm{MHz} \text {, DMSO-d6) } \delta: 137.15 ; 124.08 ; 122.74 ; 48.95 ; 45.57 ; 36.21 ; \\
31.72 ; 29.05 ; 23.27\end{array}$ & 265.2 \\
\hline IL-6 & $\begin{array}{l}{ }^{1} \mathrm{H} \text { NMR }\left(400 \mathrm{MHz}, \mathrm{DMSO}-\mathrm{d}_{6}\right)(\mathrm{ppm}) \delta: 9.32(\mathrm{~s}, 1 \mathrm{H}) ; 7.82(\mathrm{~s}, 1 \mathrm{H}) ; 7.75(\mathrm{~s}, 1 \mathrm{H}) ; \\
4.18(\mathrm{t}, J=8.0 \mathrm{~Hz}, 2 \mathrm{H}) ; 3.87(\mathrm{~s}, 3 \mathrm{H}) ; 3.63(\mathrm{t}, \mathrm{J}=8.0 \mathrm{~Hz}, 2 \mathrm{H}) ; 1.80 \text { (quintet, } \mathrm{J}= \\
8.0 \mathrm{~Hz} ; 2 \mathrm{H}) ; 1.72(\text { quintet, } J=8.0 \mathrm{~Hz} ; 2 \mathrm{H}) ; 1.41 \text { (quintet, } \mathrm{J}=8.0 \mathrm{~Hz} ; 2 \mathrm{H}) ; 1.27 \\
\text { (quintet, } J=8.0 \mathrm{~Hz} ; 2 \mathrm{H}) .{ }^{13} \mathrm{C} \text { NMR }(100 \mathrm{MHz} \text {, DMSO-d }) \delta: 137.12 ; 124.06 ; \\
\quad 122.73 ; 49.10 ; 45.73 ; 36.20 ; 32.21 ; 29.68 ; 26.07 ; 25.19\end{array}$ & 251.2 \\
\hline IL-7 & $\begin{array}{c}{ }^{1} \mathrm{H} \text { NMR }\left(400 \mathrm{MHz}, \mathrm{DMSO}-d_{6}\right)(\mathrm{ppm}) \delta: 9.51(\mathrm{~s}, 1 \mathrm{H}) ; 7.91-7.92(\mathrm{~m}, 2 \mathrm{H}) ; 4.59(\mathrm{t}, \\
J=5.6 \mathrm{~Hz}, 2 \mathrm{H}) ; 4.23-4.29(\mathrm{~m}, 2 \mathrm{H}) ; 4.12(\mathrm{t}, \mathrm{J}=5.6 \mathrm{~Hz}, 2 \mathrm{H}) ; 1.44(\mathrm{t}, \mathrm{J}=7.2 \mathrm{~Hz} \text {, } \\
3 \mathrm{H}) .{ }^{13} \mathrm{C} \text { NMR }\left(100 \mathrm{MHz}, \mathrm{DMSO}-\mathrm{d}_{6}\right) \delta: 136.92 ; 123.11 ; 122.73 ; 50.78 ; 44.79 ; \\
43.58 ; 15.54\end{array}$ & 250.7 \\
\hline IL-8 & $\begin{array}{c}{ }^{1} \mathrm{H} \text { NMR }\left(400 \mathrm{MHz}, \mathrm{DMSO}-d_{6}\right)(\mathrm{ppm}) \delta: 9.58(\mathrm{~s}, 1 \mathrm{H}) ; 7.96(\mathrm{~s}, 1 \mathrm{H}) ; 7.92(\mathrm{~s}, 1 \mathrm{H}) ; \\
4.60(\mathrm{t}, J=8.0 \mathrm{~Hz}, 2 \mathrm{H}) ; 4.24(\mathrm{t}, J=8.0 \mathrm{~Hz}, 2 \mathrm{H}) ; 4.13(\mathrm{t}, \mathrm{J}=8.0 \mathrm{~Hz}, 2 \mathrm{H}) ; 1.79 \\
\text { (quintet, } J=8.0 \mathrm{~Hz} ; 2 \mathrm{H}) ; 1.26 \text { (quintet, } J=8.0 \mathrm{~Hz} ; 2 \mathrm{H}) ; 0.90(\text { quintet, } J=8.0 \\
\mathrm{Hz} ; 3 \mathrm{H}) .{ }^{13} \mathrm{C} \text { NMR (100 MHz, DMSO-d6) } \delta: 134.34 ; 123.13 ; 123.04 ; 50.78 ; \\
49.09 ; 43.67 ; 31.76 ; 19.17 ; 13.72\end{array}$ & 249.5 \\
\hline IL-9 & $\begin{array}{c}{ }^{1} \mathrm{H} \text { NMR }\left(400 \mathrm{MHz}, \mathrm{D}_{2} \mathrm{O}\right)(\mathrm{ppm}) \delta: 3.90(\mathrm{t}, J=7.2 \mathrm{~Hz}, 2 \mathrm{H}) ; 3.60(\mathrm{t}, J=7.2 \mathrm{~Hz} \text {, } \\
2 \mathrm{H} ;) ; 3.32-3.37(\mathrm{~m}, 6 \mathrm{H}) ; 1.27(\mathrm{t}, J=7.2 \mathrm{~Hz}, 9 \mathrm{H}) .{ }^{13} \mathrm{C} \mathrm{NMR}\left(100 \mathrm{MHz}, \mathrm{D}_{2} \mathrm{O}\right) \delta: \\
56.57 ; 53.48 ; 34.86 ; 6.8\end{array}$ & 213.9 \\
\hline IL-10 & $\begin{array}{c}{ }^{1} \mathrm{H} \text { NMR }\left(400 \mathrm{MHz}, \mathrm{DMSO}-\mathrm{d}_{6}\right)(\mathrm{ppm}) \delta: 9.52(\mathrm{~s}, 1 \mathrm{H}) ; 7.89(\mathrm{~s}, 1 \mathrm{H}) ; 7.78(\mathrm{~s} \\
1 \mathrm{H}) ; 7.48-7.54(\mathrm{~m}, 4 \mathrm{H}) ; 5.50(\mathrm{~s}, 2 \mathrm{H}) ; 3.88(\mathrm{~s}, 3 \mathrm{H}) .{ }^{3} \mathrm{C} \mathrm{NMR}(100 \mathrm{MHz} \\
\left.\mathrm{DMSO}-d_{6}\right) \delta: 137.36 ; 134.47 ; 133.94 ; 130.93 ; 129.38 ; 124.46 ; 122.74 ; 51.34 ; \\
36.34\end{array}$ & 267.4 \\
\hline IL-11 & $\begin{array}{c}{ }^{1} \mathrm{H} \text { NMR }\left(400 \mathrm{MHz}, \mathrm{DMSO}-d_{6}\right)(\mathrm{ppm}) \delta: 9.23-9.25(\mathrm{~m}, 2 \mathrm{H}) ; 8.68-8.72(\mathrm{~m}, 1 \mathrm{H}) \\
\text { 8.23-8.26 }(\mathrm{m}, 2 \mathrm{H}) ; 5.07(\mathrm{t}, J=5.6 \mathrm{~Hz}, 2 \mathrm{H}) ; 4.29(\mathrm{t}, J=5.6 \mathrm{~Hz}, 2 \mathrm{H}) .{ }^{13} \mathrm{C} \mathrm{NMR} \\
\left(100 \mathrm{MHz}, \mathrm{DMSO}-d_{6}\right) \delta: 146.41 ; 145.38 ; 127.93 ; 61.09 ; 43.61\end{array}$ & 210.3 \\
\hline IL-12 & $\begin{array}{c}{ }^{1} \mathrm{H} \text { NMR }\left(400 \mathrm{MHz}, \mathrm{DMSO}-\mathrm{d}_{6}\right)(\mathrm{ppm}) \delta: 9.25(\mathrm{~s}, 1 \mathrm{H}) ; 7.83-7.84(\mathrm{~m}, 1 \mathrm{H}) ; 7.75- \\
7.76(\mathrm{~m}, 1 \mathrm{H}) ; 4.56(\mathrm{t}, J=5.6 \mathrm{~Hz}, 2 \mathrm{H}) ; 4.07(\mathrm{t}, J=5.6 \mathrm{~Hz}, 2 \mathrm{H}) ; 3.88(\mathrm{~s}, 3 \mathrm{H}) .{ }^{13} \mathrm{C} \\
\mathrm{NMR}\left(100 \mathrm{MHz}, \mathrm{DMSO}-\mathrm{d}_{6}\right) \delta: 137.2 ; 123.8 ; 122.5 ; 50.3 ; 43.1 ; 35.8\end{array}$ & 191.3 \\
\hline
\end{tabular}




\section{Typical Procedure for Cellulose Conversion}

A total of $1.62 \mathrm{~g}$ of cellulose (10 mmol of sugar units), $10 \mathrm{mmol}$ of SFIL, and 20 $\mathrm{mL}$ of $\mathrm{H}_{2} \mathrm{O}$ were poured into a $50-\mathrm{mL}$ stainless autoclave. The reactor was previously flushed with $\mathrm{N}_{2}$ three times to displace the air and then heated to a required temperature $\left(160^{\circ} \mathrm{C}\right)$ and kept at a certain time $(1 \mathrm{~h})$ with stirring $(500 \mathrm{rpm})$. When the designed reaction time was elapsed, the reactor halted and cooled down to room temperature with cool water in $10 \mathrm{~min}$.

\section{Products Analysis Procedure}

The resulting product mixture was firstly filtered, and the solid residue was obtained after the wash by $\mathrm{H}_{2} \mathrm{O}(5 \mathrm{~mL} \times 3)$ and dried until constant weight for conversion calculation. The filtrate above was diluted to $100 \mathrm{~mL}$ for quantitative analysis on high performance liquid chromatography (HPLC, Agilent 1200; Agilent Technologies, Santa Carla, CA, USA) equipped with a RID detector and a HPX-87H column $(300 \times 7.8 \mathrm{~mm})$ at $65{ }^{\circ} \mathrm{C}$, using $5 \mathrm{mM} \mathrm{H}_{2} \mathrm{SO}_{4}$ as eluent at $0.6 \mathrm{~mL} / \mathrm{min}$ flow rate. The yield of products was determined using the extra standard method with commercially available standard substrates. The cellulose conversion (Conv. wt $\%)$, yield of glucose $\left(Y_{\mathrm{Glu}} \mathrm{mol} \%\right)$, LA ( $Y_{\mathrm{LA}}$ mol\%), and FA ( $Y_{\mathrm{FA}} \mathrm{mol} \%$ ) were calculated according to Eqs. 1 through 4, respectively,

$$
\begin{aligned}
& \text { Conv. }(\mathrm{wt} \%)=\frac{M_{\mathrm{R}}}{M_{\mathrm{F}}} \times 100 \% \\
& Y_{\mathrm{Glu}}(\mathrm{mol} \%)=\frac{N_{\mathrm{Glu}}}{M_{\mathrm{F}} / 162} \times 100 \% \\
& Y_{\mathrm{LA}}(\mathrm{mol} \%)=\frac{N_{\mathrm{LA}}}{M_{\mathrm{F}} / 162} \times 100 \% \\
& Y_{\mathrm{FA}}(\mathrm{mol} \%)=\frac{N_{\mathrm{FA}}}{M_{\mathrm{F}} / 162} \times 100 \%
\end{aligned}
$$

where $M_{\mathrm{F}}$ and $M_{\mathrm{R}}$ are the weight (g) of feed cellulose and residue, respectively, $N_{\mathrm{Glu}}, N_{\mathrm{LA}}$, and $N_{\mathrm{FA}}$ are the moles of yielded glucose, LA, and FA, respectively, and were calculated through HPLC analysis. The data listed in this paper show the mean values with standard deviations according to the three independent reactions.

\section{The Reuse Procedure}

After the first reaction, the FA in filtrate was recovered firstly through a rotary evaporation; and then the LA that was present in the resulting mixture was extracted by ethyl acetate $(5 \mathrm{~mL} \times 3)$; lastly, the residual viscous liquid containing SFILs, glucose, and others were reused without further purification. For facilitating quantification of glucose, LA, and FA yield, a negligible portion $(100 \mu \mathrm{L})$ of filtrate can be taken out and diluted to $1 \mathrm{~mL}$ with water for HPLC analysis.

\section{RESULTS AND DISCUSSION}

\section{Conversion of MCC in the Presence of Various CFILs}

The effect of CFILs on the conversion of MCC into LA was investigated primarily, and the results are given in Fig. 2. 


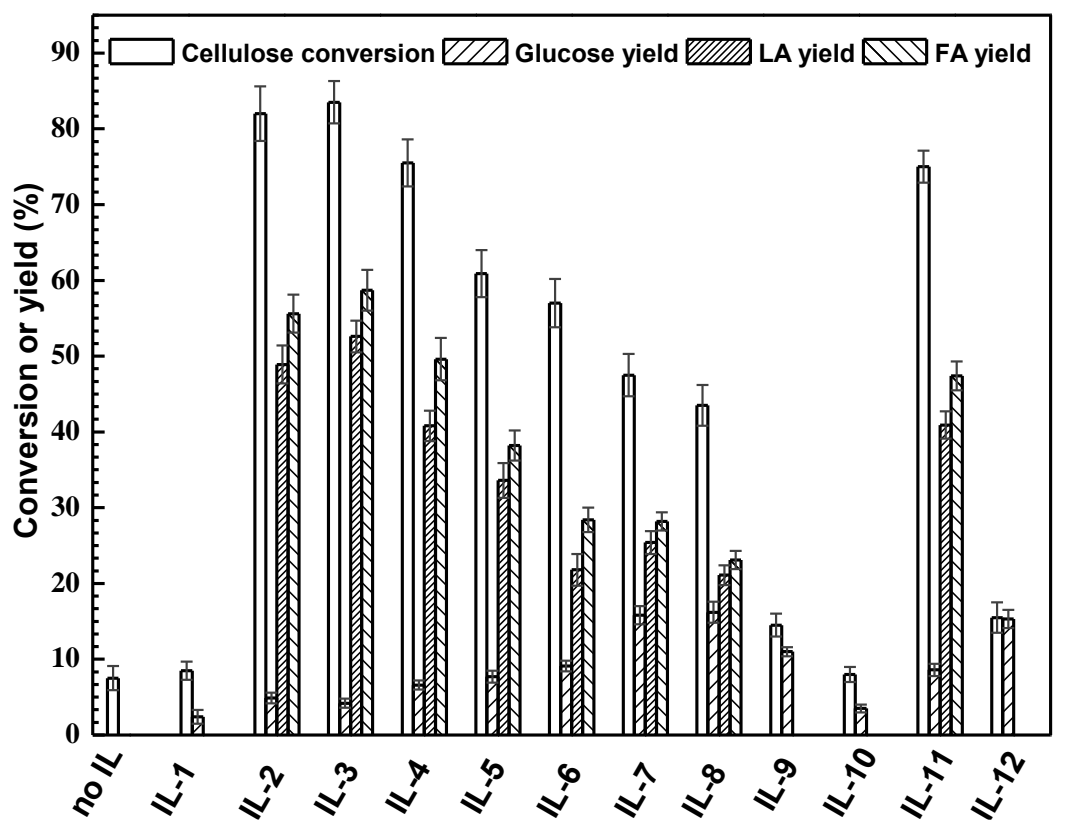

Fig. 2. The promotion of CFILs on cellulose conversion (Conditions: $1.62 \mathrm{~g}$ of MCC, $10.0 \mathrm{mmol}$ of $\mathrm{IL}, 20.0 \mathrm{~mL}$ of $\mathrm{H}_{2} \mathrm{O}, 160^{\circ} \mathrm{C}$ for $1 \mathrm{~h}$ )

As shown in Fig. 2, the conversion of cellulose was only $8.5 \%$ accompanying with $2.4 \%$ of glucose yield in the presence of non-chloro-functionalized IL-1. This result was comparable with a reaction system without any additives (no IL), implying the promotion effect of IL-1 for cellulose hydrolysis can be negligible. It is noteworthy that $82.0 \%$ of cellulose could be converted into $4.9 \%, 48.9 \%$, and $55.6 \%$ of glucose, LA, and FA, respectively, enhanced by the added chloro-functionalized IL-2. These results show clearly that $-\mathrm{Cl}$ groups on IL-2 play the key role for cellulose conversion, possibly due to its adsorption on cellulose through the hydrogen bond, resulting in efficiently lowering the activity energy of cellulose conversion (Shuai and Pan 2012; Tyufekchiev et al. 2018; Zhang et al. 2019).

Encouraged by the results above, a series of CFILs with different alkyl chains in the imidazolium ring were investigated intensively (IL-3 through IL-8). IL-3 with chloropropyl linker had a little more promotion effect on cellulose conversion than that IL-2, giving the $83.5 \%$ of cellulose conversion with $4.2 \%, 52.6 \%$, and $58.7 \%$ of glucose, LA, and FA yields, respectively. However, when further increasing the length of chloroalkyl linkers (IL-4 through IL-6), both conversion of cellulose and yield of LA and FA decreased in line. These findings demonstrate that the three carbon separation from the imidazole nucleus to the $-\mathrm{Cl}$ group gives a better approach of the positive imidazole nucleus to glycosidic oxygen and the $-\mathrm{Cl}$ group to glycosidic $-\mathrm{OH}$ for their activation, as compared to other carbon arms (Amarasekara and Owereh 2009). Shorter or longer chloroalkyl linkers can prohibit the compatibility and co-operation between positive imidazole nucleuses and $-\mathrm{Cl}$ groups. In addition, the steric hindrance of cations with much longer chloro-alkyl linkers is another reason for the poor compatibility and co-operation and can be confirmed by comparison analysis of IL-2 with IL-7 and IL-8, whose N'-alkyl is replaced by N'-ethyl and N'-butyl, respectively. As expected, the promotion effect of IL7 and IL-8 on cellulose conversion declined as increasing of $\mathrm{N}^{\prime}$-alkyl chain length and 
were all much less than that of IL-2. IL-9 and IL-10 with much bigger tridimensional sizes gave the promotion less than that of IL-11 with the similar size of IL-2 also confirming the reasonable conclusions above. However, as the $\mathrm{Cl}^{-}$anion of IL-2 was replaced by $\mathrm{NO}_{3}{ }^{-}$ anion (IL-12), the promotion effect on cellulose hydrolysis declined remarkably, implying $-\mathrm{Cl}$ groups were not able to convert cellulose into LA solely. Hence, the co-operation between $-\mathrm{Cl}$ groups on cations of ILs with appropriate size and $\mathrm{Cl}^{-}$anion is indispensable for the production of LA from cellulose.

\section{The Influence of Other Additives}

To understand the synergy mechanism between cations and anions of CFILs on cellulose conversion, the contribution of anion was demonstrated through the addition of salts with different anions.

Table 2. Effect of Additives on Cellulose Conversion

\begin{tabular}{|c|c|c|c|c|c|c|}
\hline \multirow{2}{*}{ Entry } & \multirow{2}{*}{$\begin{array}{c}\mathrm{IL}-3 \\
(\mathrm{mmol})\end{array}$} & \multirow{2}{*}{$\begin{array}{l}\text { Additives } \\
\text { (mmol) }\end{array}$} & \multirow{2}{*}{$\begin{array}{l}\text { Conversion } \\
\text { (wt\%) }\end{array}$} & \multicolumn{3}{|c|}{ Yield (mol\%) } \\
\hline & & & & Glucose & LA & FA \\
\hline 1 & 5 & I & $56.2 \pm 1.9$ & $6.8 \pm 1.1$ & $23.7 \pm 1.8$ & $25.4 \pm 1.7$ \\
\hline 2 & 10 & I & $83.5 \pm 2.8$ & $4.2 \pm 0.6$ & $52.6 \pm 2.1$ & $58.7 \pm 2.7$ \\
\hline 3 & 15 & I & $89.6 \pm 2.1$ & $2.3 \pm 0.5$ & $58.9 \pm 2.6$ & $66.5 \pm 2.2$ \\
\hline 4 & l & $\mathrm{NaCl}(10)$ & $11.4 \pm 2.8$ & $2.9 \pm 0.3$ & ND & ND \\
\hline 5 & 5 & $\mathrm{NaCl}(5)$ & $72.5 \pm 2.3$ & $4.4 \pm 0.7$ & $33.0 \pm 1.4$ & $51.3 \pm 1.9$ \\
\hline 6 & 5 & $\mathrm{NaCl}(10)$ & $82.0 \pm 2.1$ & $4.3 \pm 0.5$ & $43.4 \pm 1.2$ & $52.8 \pm 1.5$ \\
\hline 7 & 5 & $\mathrm{NaCl}(20)$ & $87.1 \pm 2.6$ & $4.0 \pm 0.2$ & $48.1 \pm 1.4$ & $55.8 \pm 1.8$ \\
\hline 8 & 5 & $\mathrm{NaBr}(10)$ & $70.8 \pm 2.7$ & $4.1 \pm 0.6$ & $33.1 \pm 1.5$ & $32.9 \pm 1.2$ \\
\hline 9 & 5 & $\mathrm{Nal}(10)$ & $67.5 \pm 2.8$ & $2.5 \pm 09$ & $31.0 \pm 1.6$ & $31.6 \pm 1.4$ \\
\hline 10 & 5 & HCOONa (10) & $7.5 \pm 1.9$ & $2.7 \pm 0.7$ & trace & ND \\
\hline 11 & 5 & $\begin{array}{c}\mathrm{CH}_{3} \mathrm{COONa} \\
(10)\end{array}$ & $8.0 \pm 1.2$ & $2.4 \pm 0.3$ & ND & ND \\
\hline 12 & 5 & $\mathrm{FA}(10)$ & $39.7 \pm 1.9$ & $4.3 \pm 0.6$ & $16.3 \pm 1.2$ & $19.2 \pm 1.6$ \\
\hline 13 & 5 & LA (10) & $30.5 \pm 1.3$ & $4.0 \pm 0.2$ & $12.1 \pm 1.6$ & $16.4 \pm 1.5$ \\
\hline 14 & 1 & FA (10) & $11.0 \pm 1.8$ & $0.5 \pm 0.3$ & ND & - \\
\hline 15 & 1 & LA (10) & $10.6 \pm 1.2$ & $0.4 \pm 0.1$ & - & ND \\
\hline
\end{tabular}

As shown in Table 2, the IL-3 dosage had a noticeable impact on its promotion effect for converting cellulose (Entries 1 through 3). Additionally, to study the influence of anion exactly, the IL-3 dosage was set to $5 \mathrm{mmol}$ because of the moderate conversion of cellulose $(56.2 \%)$ at this point (Entry 1). In addition, $\mathrm{NaCl}$ accelerated cellulose hydrolysis negligibly under conventional heating conditions due to its comparable promotion effect with that of IL-1. Herein, $\mathrm{NaCl}$ can be used as the $\mathrm{Cl}^{-}$source for elevating the $\mathrm{Cl}^{-}$content only without obvious acceleration effect in this system.

It was noteworthy that, as the additional amount of $\mathrm{Cl}^{-}$content increased from 0 to $20 \mathrm{mmol}$, the cellulose conversion and the target products yield increased expectedly (Entries 1 and 5 through 7). These results are in good accord with the earlier report (Potvin 
et al. 2011), and show that increased $\mathrm{Cl}^{-}$content improved the efficiency of the cooperation between $-\mathrm{Cl}$ groups on cations and $\mathrm{Cl}^{-}$anions, resulting in promotion of cellulose conversion. Furthermore, the $\mathrm{Br}^{-}$and $\mathrm{I}^{-}$anions also presented certain promotion effect on cellulose conversion. For examples, $\mathrm{NaBr}$ and $\mathrm{NaI}$ additives could elevate the conversion efficiency of cellulose obviously (Entries 8 and 9); the cellulose conversion and products yield were higher than that without additives under the same reaction conditions (Entry 1). But the promotion of $\mathrm{Br}^{-}$and $\mathrm{I}^{-}$anions on cellulose conversion was weaker than $\mathrm{Cl}^{-}$due to their weak hydrogen bond accepting abilities (Wang et al. 2012; Zhao et al. 2013), which lessens the co-operation of $\mathrm{Br}^{-} / \mathrm{I}^{-}$anions with $-\mathrm{Cl}$ groups (Entry 6,8 and 9).

However, as $\mathrm{HCOO}^{-}$and $\mathrm{CH}_{3} \mathrm{COO}^{-}$were added into the reaction systems, the promotion effect of IL-3 was lost, leaving less than $10 \%$ of cellulose conversion and less than $3 \%$ of glucose yield as detected (Entries 10 and 11). These findings demonstrate $\mathrm{HCOO}^{-}$and $\mathrm{CH}_{3} \mathrm{COO}^{-}$with the stronger hydrogen bond basicity than $\mathrm{Cl}^{-}$can noticeably prohibit the co-operation between cations and anions of IL-3 (Fukaya et al. 2006). Moreover, the presence of organic acid, such as FA and LA, can also give the inhibition effect for cellulose conversion possibly due to the existence of anions from the dissociation of FA and LA, implying that the generated LA and FA may have a negative effect on cellulose conversion (Entries 12 through 15), and the separation of LA and FA in situ will be helpful to elevate their yields as the reaction proceeds. Hence, based on the results above, the synergy effect between $-\mathrm{Cl}$ groups on cations and $\mathrm{Cl}^{-}$anions of CFILs is the key factor in efficiently enhancing LA production from cellulose.

\section{The Reusability of IL-3}

Due to the high cost of ILs, the reusability of the ILs-based promotion additive is important for applying in industrial biorefinery processes. Hence, the recyclability performance of IL-3 was evaluated as a model.

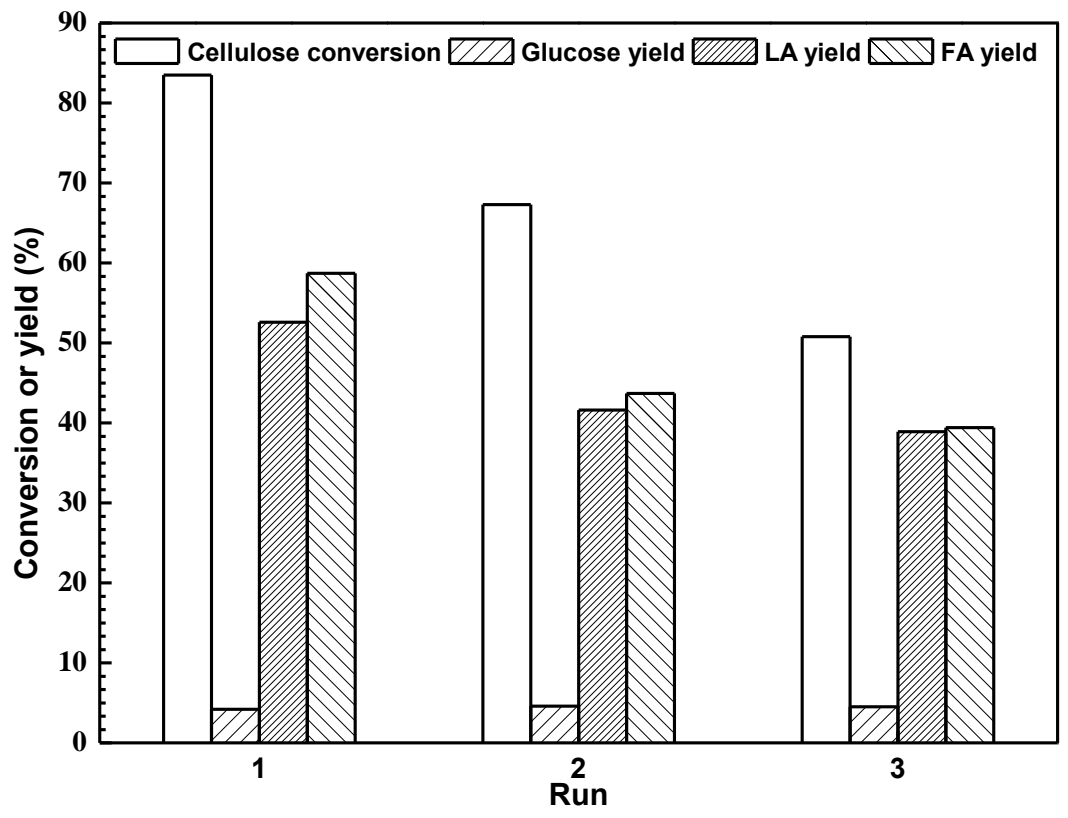

Fig. 3. The reusability of IL-3 (Conditions: $10 \mathrm{mmol}$ of IL-3, $1.62 \mathrm{~g}$ of MCC, $20.0 \mathrm{~mL}$ of $\mathrm{H}_{2} \mathrm{O}, 160$ ${ }^{\circ} \mathrm{C}$ for $1 \mathrm{~h}$ ) 
As shown in Fig. 3, the recyclability performance of IL-3 declined with the number of recycles, and only $50.8 \%$ of cellulose was converted into $4.5 \%, 38.9 \%$, and $39.4 \%$ of glucose, LA, and FA, respectively, at the third run. The decrease in recyclability of IL-3 is probably due to the presence of humins or other soluble polymers from the last run (Patil et al. 2012), which can compete with cellulose in bonding to $-\mathrm{Cl}$ groups or $\mathrm{Cl}^{-}$anions, resulting in little chance for co-operation between $-\mathrm{Cl}$ groups and $\mathrm{Cl}^{-}$anions on cellulose conversion. Although the recyclability of IL-3 is unsatisfied, it is still active in each recycling run, indicating the stability of the $-\mathrm{Cl}$ groups and the reusability of SFILs. To improve the recyclability performance of SFILs, the new separation technologies should be explored necessarily. The study on process parameters, promotion mechanism, substrate types, and recovery of SFILs is ongoing in the authors' lab, and will be reported soon

\section{CONCLUSIONS}

1. The moderate length of chloro-alkyl linkers on cations in chloro-functionalized ionic liquids (CFILs) is necessary to promote the conversion of cellulose with high efficiency.

2. 3-(3-chloropropyl)-1-methyl-imidazolium chloride (IL-3) showed the highest promotion effect for cellulose conversion.

3. $52.6 \%$ of levulinic acid (LA) and $58.7 \%$ of formic acid (FA) were obtained in the presence of IL-3.

4. The co-operation between $-\mathrm{Cl}$ groups on cations and $\mathrm{Cl}^{-}$anions of CFILs is indispensable for cellulose conversion.

\section{ACKNOWLEDGMENTS}

The authors gratefully acknowledge the financial support of the Natural Science Foundation of China (21808043), the Natural Science Foundation of Guangdong Province, China (2018A030307055, 2020A151501145), and the Ordinary University Innovation Project of Guangdong Province, China (2017KQNCX131, 2018KTSCX151, and 2015KTSCX091).

\section{REFERENCES CITED}

Amarasekara, A. S. (2016). “Acidic ionic liquids,” Chem. Rev. 116(10), 6133-6183. DOI: 10.1021/acs.chemrev.5b00763

Amarasekara, A. S., and Owereh, O. S. (2009). "Hydrolysis and decomposition of cellulose in Bronsted acidic ionic liquids under mild conditions," Ind. Eng. Chem. Res. 48(22), 10152-10155. DOI: 10.1021/ie901047u

Bonhote, P., Dias, A.-P., Papageorgiou, N., Kalyanasundaram, K., and Grätzel, M. (1996). "Hydrophobic, highly conductive ambient-temperature molten salts," Inorgan. Chem. 35(5), 1168-1178. DOI: 10.1021/ic951325x 
Bozell, J. J., and Petersen, G. R. (2010). "Technology development for the production of biobased products from biorefinery carbohydrates - the US Department of Energy's "Top 10" revisited," Green Chem. 12(4), 539-554. DOI: 10.1039/B922014C

Deng, W., Zhang, Q., and Ye, W. (2015). "Catalytic transformations of cellulose and its derived carbohydrates into 5-hydroxymethylfurfural, levulinic acid, and lactic acid," Sci. China- Chem. 58(1), 29-46. DOI: 10.1007/s11426-014-5283-8

Fukaya, Y., Sugimoto, A., and Ohno, H. (2006). "Superior solubility of polysaccharides in low viscosity, polar, and halogen-free 1,3-dialkylimidazolium formates," Biomacromolecules 7(12), 3295-3297. DOI: 10.1021/bm060327d

Kilpelainen, I., Xie, H., King, A. W. T., Granstrom, M., Heikkinen, S., and Argyropoulos, D. S. (2007). "Dissolution of wood in ionic liquids," J. Agr. Food Chem. 55(22), 9142-9148. DOI: 10.1021/jf071692e

Ma, H., Liao, C., Yang, P., Qiao, Y., Li, N., and Teng, J. (2018). “Eco-friendly production of 5-hydroxymethylfurfural from sucrose using commercially available dihydric phosphate as a catalyst," ChemistrySelect 3(43), 12113-12121. DOI: 10.1002/slct.201801814

Ma, H., Wang, F., Yu, Y., Wang, L., and Li, X. (2015). “Autocatalytic production of 5hydroxymethylfurfural from fructose-based carbohydrates in a biphasic system and its purification," Ind. Eng. Chem. Res. 54(10), 2657-2666. DOI: 10.1021/ie504791x

Ma, H., Zhou, B., Li, Y., and Argyropoulos, D. S. (2012). "Conversion of fructose to 5hydroxymethylfurfural with a functionalized ionic liquid," BioResources 7(1), 533544. DOI: 10.15376/biores.7.1.0533-0544

Patil, S. K. R., Heltzel, J., and Lund, C. R. F. (2012). "Comparison of structural features of humins formed catalytically from glucose, fructose, and 5hydroxymethylfurfuraldehyde," Energ. Fuel. 26(8), 5281-5293. DOI: 10.1021/ef3007454

Potvin, J., Sorlien, E., Hegner, J., DeBoef, B., and Lucht, B. L. (2011). "Effect of NaCl on the conversion of cellulose to glucose and levulinic acid via solid supported acid catalysis," Tetrahedron Lett. 52(44), 5891-5893. DOI: 10.1016/j.tetlet.2011.09.013

Rackemann, D. W., and Doherty, W. O. S. (2011). "The conversion of lignocellulosics to levulinic acid," Biofuel. Bioprod. Bior. 5(2), 198-214. DOI: 10.1002/bbb.267

Shaveta Bansal, N., and Singh, P. (2014). " $\mathrm{F}^{-} / \mathrm{Cl}^{-}$mediated microwave assisted breakdown of cellulose to glucose," Tetrahedron Lett. 55(15), 2467-2470. DOI: 10.1016/j.tetlet.2014.03.006

Shuai, L., and Pan, X. (2012). "Hydrolysis of cellulose by cellulase-mimetic solid catalyst," Energ. Environ. Sci. 5(5), 6889-6894. DOI: 10.1039/C2EE03373A

Song, G., Wang, X., Li, Y., and Li, X. (2008). "Iridium abnormal N-heterocyclic carbene hydrides via highly selective C-H activation," Organometallics 27(6), 1187-1192. DOI: $10.1021 /$ om7011216

Tao, F., Song, H., and Chou, L. (2011). "Catalytic conversion of cellulose to chemicals in ionic liquid,” Carbohyd. Res. 346(1), 58-63. DOI: 10.1016/j.carres.2010.10.022

Teng, J., Ma, H., Wang, F., Wang, L., and Li, X. (2016). "Catalytic fractionation of raw biomass to biochemicals and organosolv lignin in a methyl isobutyl ketone $/ \mathrm{H}_{2} \mathrm{O}$ biphasic system," ACS Sustainable Chem. Eng. 4(4), 2020-2026. DOI: 10.1021/acssuschemeng.5b01338

Tyufekchiev, M. V., Pu, D., Schmidt-Rohr, K., Granados-Focil, S., and Emmert, M. H. (2018). "Cellulase-inspired solid acids for cellulose hydrolysis: Structural 
explanations for high catalytic activity," ACS Catal. 8(2), 1464-1468. DOI:

10.1021/acscatal.7b04117

Wang, C., Fu, L., Tong, X., Yang, Q., and Zhang, W. (2012). "Efficient and selective conversion of sucrose to 5-hydroxymethylfurfural promoted by ammonium halides under mild conditions," Carbohyd. Res. 347(1), 182-185. DOI: 10.1016/j.carres.2011.11.013

Wilkes, J. S., and Zaworotko, M. J. (1992). "Air and water stable 1-ethyl-3methylimidazolium based ionic liquids," Chem. Commun. 1992(13), 965-967. DOI: 10.1039/C39920000965

Zhang, L., Tian, L., Sun, R., Liu, C., Kou, Q., and Zuo, H. (2019). "Transformation of corncob into furfural by a bifunctional solid acid catalyst," Bioresource Technol. 276, 60-64. DOI: 10.1016/j.biortech.2018.12.094

Zhang, Z., Song, J., and Han, B. (2016). "Catalytic transformation of lignocellulose into chemicals and fuel products in ionic liquids," Chem. Rev. 117(10), 6834-6880. DOI: 10.1021/acs.chemrev.6b00457

Zhao, Y., Liu, X., Wang, J., and Zhang, S. (2013). "Effects of anionic structure on the dissolution of cellulose in ionic liquids revealed by molecular simulation," Carbohydr. Polym. 94(2), 723-730. DOI: 10.1016/j.carbpol.2013.02.011

Zuo, Y., Zhang, Y., and Fu, Y. (2014). "Catalytic conversion of cellulose into levulinic acid by a sulfonated chloromethyl polystyrene solid acid catalyst," ChemCatChem. 6(3), 753-757. DOI: $10.1002 /$ cctc.201300956

Article submitted: July 31, 2020; Peer review completed: September 27, 2020; Revised version received and accepted: October 12, 2020; Published: October 16, 2020.

DOI: 10.15376/biores.15.4.9155-9165 